\title{
PHYSICAL AND NUMERICAL ANALYSIS ON THE MECHANICAL BEHAVIOR OF COVER-COLLAPSE SINKHOLES IN CENTRAL FLORIDA
}

\author{
Moataz H. Soliman \\ Department of Civil, Environmental, and Construction Engineering, University of Central Florida, 4000 Central \\ Florida Blvd, Orlando, FL 32816, U.S.A, moatazhs@knights.ucf.edu
}

\section{Adam L. Perez}

Department of Civil, Environmental, and Construction Engineering, University of Central Florida, 4000 Central Florida Blvd, Orlando,FL 32816,U.S.A, alperez87@knights.ucf.edu

\section{Boo Hyun Nam}

Department of Civil, Environmental, and Construction Engineering, University of Central Florida, 4000 Central Florida Blvd, Orlando, FL 32816, U.S.A, boohyun.nam@ucf.edu (corresponding author)

\section{Ming Ye \\ Department of Scientific Computing and Geophysical Fluid Dynamics Institute, Florida State University, Tallahassee, FL 32306, U.S.A, mye@fsu.edu}

\begin{abstract}
The behavior of cover-collapse sinkholes in Central Florida was investigated in this research by both physical and numerical methods. In the physical model, a head drop between the unconfined aquifer and the confined aquifer was applied, and the cavity propagation due to a fracture at the boundary between the two aquifers was visually monitored. The cavity grew upwards in an inverted triangle shape until ground surface collapse occurred. The same cavity shape was then incorporated into the numerical study. A stress-seepage coupled analysis was carried out using GeoStudio modules: SEEP/W and SIGMA/W, simultaneously. The stress conditions during sinkhole formation were assessed at different groundwater conditions and cavity sizes. Stress redistributions were observed around the cavity due to soil arching. The effective stress significantly increases at the corners of the cavity to compensate for a stress reduction above the center of the cavity. Highest recharge values and seepage forces occur around the cavity corners. The stress paths at the corners show that the stability decreases when the cavity height increases, even when the overburden thickness decreases. Additionally, the side angles of the cavity affect the stress conditions around it.
\end{abstract}

\section{Introduction}

Sinkholes are a common geohazard in karst terrain which threaten human life and infrastructure throughout the world approximately $20 \%$ of the United States has karst features where residual soils are underlain by soluble carbonate rocks. Cavities develop at the interface between the residual soils and bedrock by a soil erosion process which ultimately leads to ground failure (Newton \& Hyde, 1971; Newton, 1976, 1984; Williams \& Vineyard, 1976). According to the USGS, the most damage from sinkholes tends to occur in Florida, Texas, Alabama, Missouri, Kentucky, Tennessee, and Pennsylvania. Florida Geological Survey classifies sinkholes in Florida into three major types: covercollapse, cover-subsidence, and dissolution. The most dramatic type is the cover-collapse due to its abrupt behavior. The collapse occurs when a subterranean cavity grows until the overburden thickness above the cavity becomes too thin for soil arching to be maintained.

In Florida, the groundwater flow triggers the growth of subterranean cavities by erosion and increases the instability of the system by seepage forces. Florida's aquifer system consists of an unconfined surficial aquifer (residual soil layer) overlying the confined Upper Floridan Aquifer (bedrock layer) which is the main source of groundwater withdrawn for usage purposes. The water level in the surficial aquifer is highly influenced by the rapid infiltration of rainwater due to the relatively high hydraulic conductivity of this soil layer. However, the hydraulic conductivity in the Upper Floridan Aquifer, which is mainly composed of limestone, is relatively low. Therefore, the head of water in the residual soil (surficial aquifer) is usually greater than that in the limestone (Upper Floridan Aquifer) which results in downward seepage (recharge). Wilson and Beck (1992) observed that $85 \%$ of new sinkholes in the Orlando area occurred within areas of high groundwater recharge. Whitman and his team (1999) examined the spatial interrelationships of head difference between 
the surficial and Upper Floridan Aquifer and sinkhole occurrences in Central Florida, where head differences ranged between $5 \mathrm{~m}$ and $15 \mathrm{~m}$.

Subterranean cavities were often modeled and simplified as circular voids, which has been commonly adopted in numerical modeling of sinkholes (Yang \& Drumm, 2002; Drumm et al., 2009). However, experimental studies on cover-collapse sinkholes (Tao et al., 2015; Perez et al., 2017) show that a cavity tends to develop as an inverted triangle with a curve-shaped roof. Most investigations of sinkholes often emphasized on the dome stability as a stability/failure problem without considering the soil behavior during sinkhole formation from the stress distribution perspective. Additionally, the sinkhole stability problem has been mostly studied in dry conditions assuming the groundwater level was below the cavities (Yang and Drumm, 2002; Drumm et al., 2009).

The stress redistributions around an underground opening are often governed by the soil arching effect (Tien, 1996). Terzaghi (1943) defined the arching effect as: "the transfer of pressure from a yielding mass onto adjoining stationary parts". Therefore, the stress redistributions around subterranean openings commonly lead to a stress reduction above the opening, and consequently a stress increase at its sides. This results in high shear stresses in the residual soil on the sides of the cavity which may cause plastic flow (yielding).

In this paper, cover-collapse sinkholes are investigated experimentally and numerically. The behavior of cavity growth and shape is determined from the laboratory study then a numerical model is implemented to assess the soil behavior around the cavity. The study included the effects of the downward seepage and water level variation on the stress distributions and the stress paths at different locations around the cavity. The coupled stress-seepage analysis is performed using two modules of the finite element software GeoStudio: SEEP/W and SIGMA/W

\section{Physical Simulation}

The schematic diagram of the sinkhole physical model testing setup is shown in Figure 1. The overall volume of the model is 60 inches $x 40$ inches x 7.5 inches. The designated volume for soil placement is 36 " x 24 " x 6 ". The model comprises of an unconfined and a confined aquifer. The aquifers are connected by a $1 / 4$ " wide and 5 " long cut in the internal floor that supports the soil and simulates the fracture in the limestone. Valves are installed on both sides of the unconfined aquifer and one at the bottom of the confined aquifer as seen in Figure 1(a). The valves are connected to a constant head system as shown in Figure 1(b). A soil constructed from a 3:1 mixture of AASHTO rated A-3 and A-2-4 soils is used in the model. The soil has an optimum moisture content of $11 \%$ and a maximum dry unit weight of $16.8 \mathrm{kN} / \mathrm{m}^{3}$. After compacting the soil to a Standard Proctor relative density of approximately $93 \%$ and leveling off the soil surface, the overburden thickness was approximately 43 $\mathrm{cm}$. The soil is then allowed to saturate for a minimum of 48 hours after slowly raising the water levels in both aquifers. To initiate sinkhole formation, downward seepage is produced by lowering the head in the confined aquifer, causing the overburden to erode through the cut in the internal floor.

Figure 2 displays the evolution of a cover-collapse sinkhole. Stage 1 shows the initial conditions before the simulation started. 16 seconds after opening the valve to lower the confined aquifer to apply a $3 \mathrm{~cm}$ drop in head, it was noticed that the soil started eroding through the cut. 6 minutes into the experiment a small void became visible (Stage 2). Stage 3 was the most critical stage where the void continued to grow larger due to the erosion process, forming an inverted triangular shaped cavity which enlarged (with the sides inclined around $50^{\circ}$ from the horizontal) until collapse took place in Stage 4. During Stage 3, the upward cavity growth was mostly evolving from the corners where the erosion process was most obvious. However, no visible signs of surface settlement took place during Stage 3 until a couple of minutes before the surface collapse, which occurred after 33 minutes. As the near surface soils dried up, the 2nd failure occurred, thus the size of the sinkhole was now significant (Stage 5). In this last stage, an increase in the groundwater level occurred and a pond was subsequently formed; by this time the sinkhole was no longer active.

\section{Numerical Simulation}

The numerical model was executed to maintain a similar cavity shape to that observed in the physical study. The configuration of the model is shown in Figure 3. The height and width of the model are $30 \mathrm{~m}$ and 60 $\mathrm{m}$, respectively. The cavity has a symmetric triangular shape, and its sides make an angle of $51^{\circ}$ with the bottom horizontal boundary. Two different cavity heights were analyzed in this study: $4 \mathrm{~m}$ and $8 \mathrm{~m}$. The residual soil layer is modeled as a single homogeneous layer. Zero vertical and horizontal displacements are assumed at the bottom boundary representing the relatively stiff bedrock. The soil is assigned the properties shown in Table 1. These properties are determined from correlations based on field testing data obtained from the Wekiwa area in Central Florida (Shamet et al., 2017). 

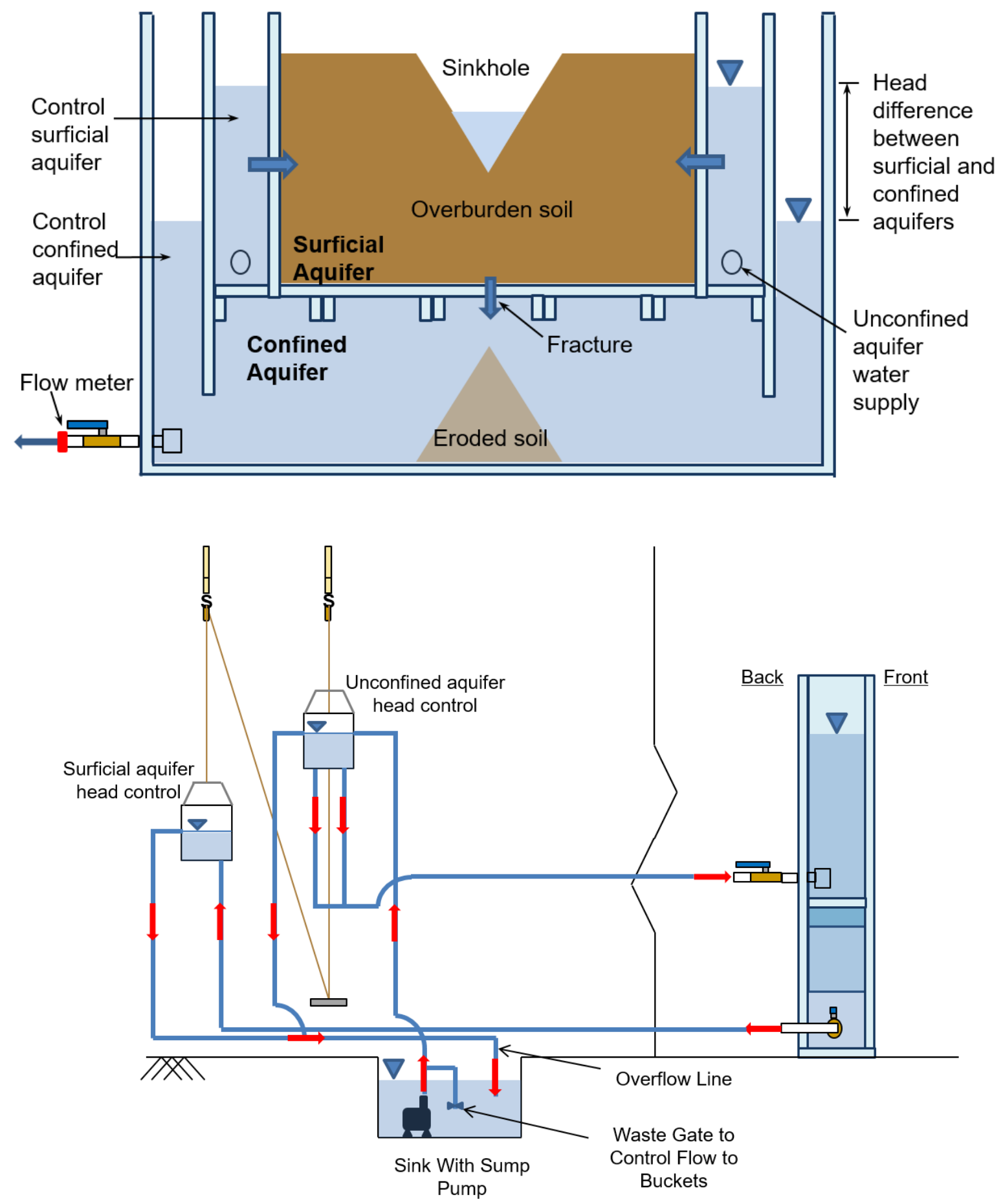

Figure 1. Setup of physical model. (a) Valves are installed on both sides of the unconfined aquifer and one at the bottom of the confined aquifer. (b) Valves are connected to a constant head system 

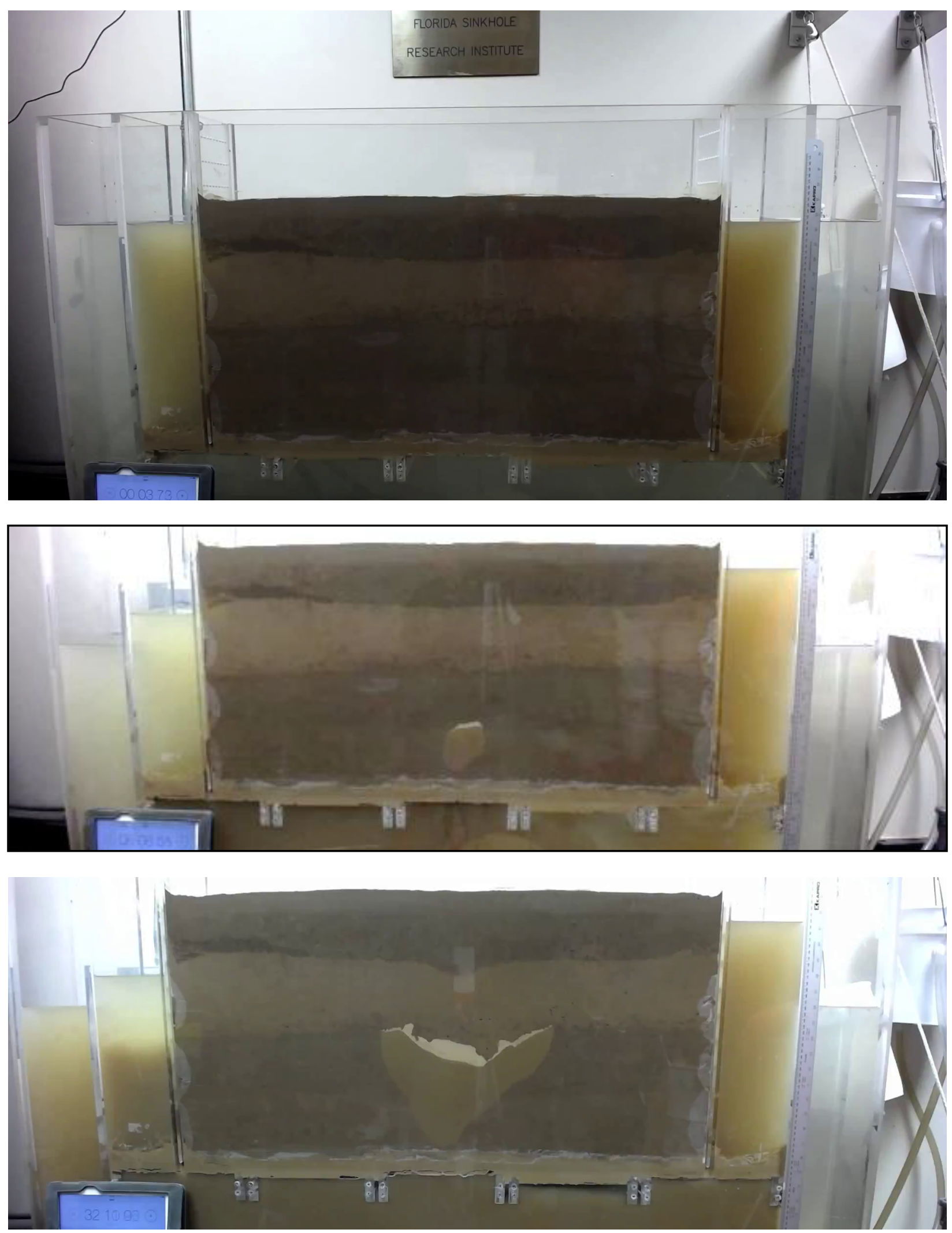

Figure 2. Physical simulation of a cover-collapse sinkhole (a) Stage 1: Test Setup (b) Stage 2: Cavity Initiates (c) Stage 3: Cavity Grows Toward the Surface (Continued on next page) 


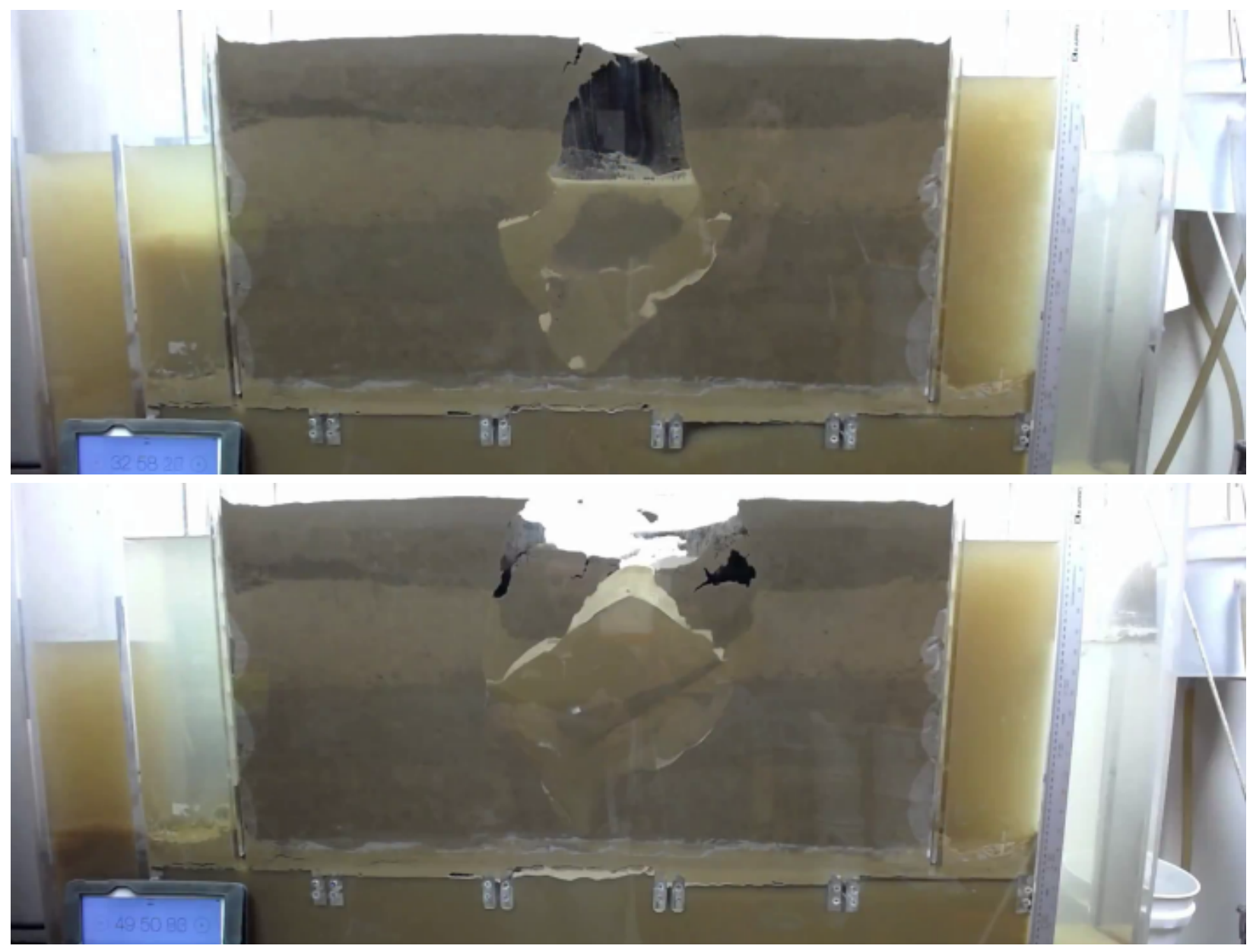

Figure 2. Physical simulation of a cover-collapse sinkhole. (d) Stage 4: Surface Collapse (e) Stage 5: Second Failure and Pond Formation

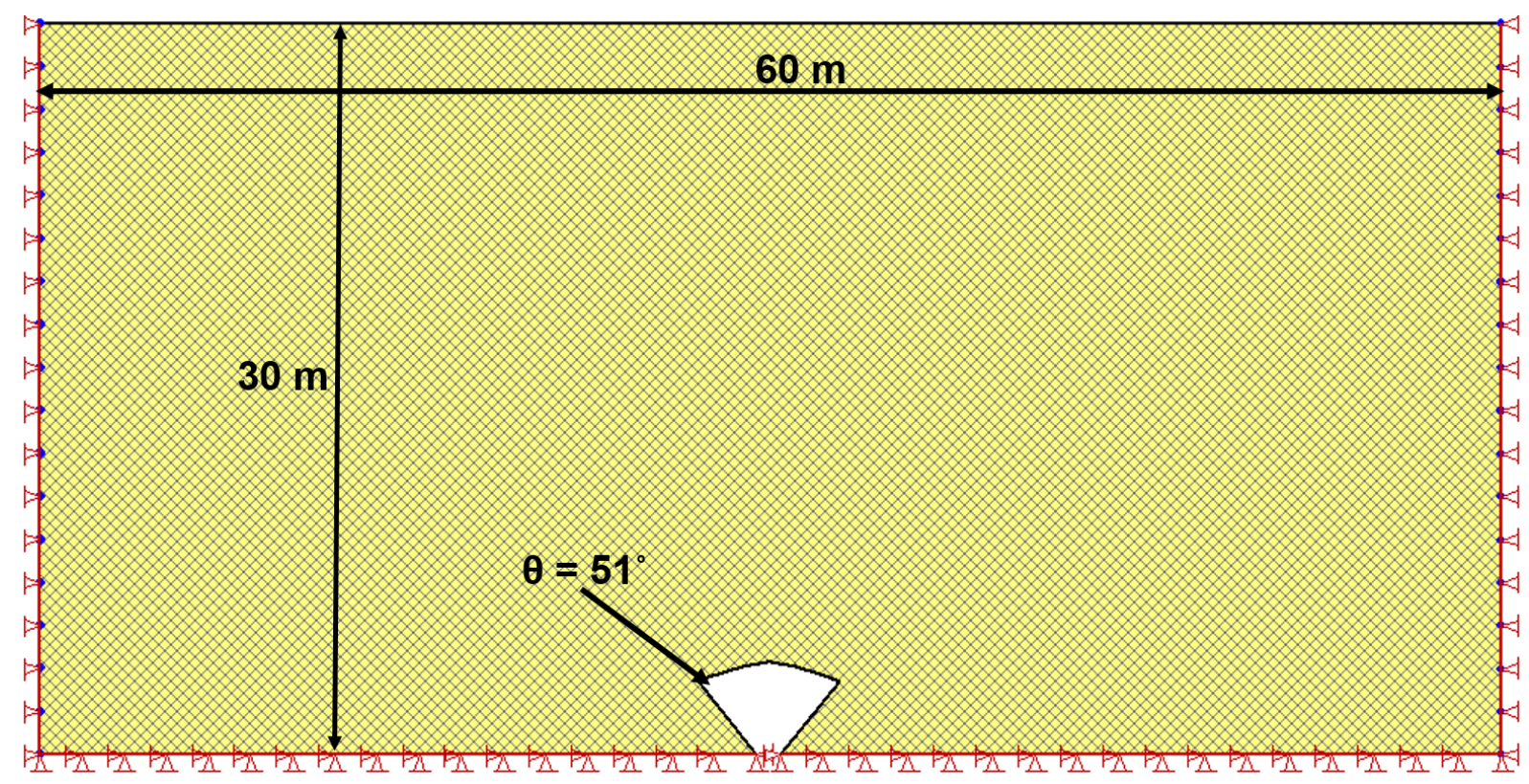

Figure 3. Numerical model 


\begin{tabular}{|c|c|}
\hline Parameter & Value \\
\hline Cohesion $(\mathrm{kPa})$ & 50 \\
\hline Friction Angle $\left(^{\circ}\right)$ & 30 \\
\hline Young's Modulus (kPa) & 7000 \\
\hline Poisson's Ratio & 0.333 \\
\hline Density $\left(\mathrm{kN} / \mathrm{m}^{3}\right)$ & 18 \\
\hline Saturated Hydraulic Conductivity $(\mathrm{m} / \mathrm{sec})$ & $1 \times 10-6$ \\
\hline
\end{tabular}

Table 1. Values of soil parameters
SEEP/W and SIGMA/W were simultaneously used in order to conduct a seepage-stress coupled analysis. The side boundaries of the model were assigned a total head value of $28 \mathrm{~m}$ to generate the initial hydrostatic water level. Total head values of $23 \mathrm{~m}, 18 \mathrm{~m}$, and $13 \mathrm{~m}$ were used at the cavity boundaries in order to simulate the recharge (downward seepage) conditions, creating head differences of $5 \mathrm{~m}, 10 \mathrm{~m}$, and $15 \mathrm{~m}$, respectively. For each head difference, transient analysis was carried out until steady-state was reached. Figure 4 shows the groundwater drawdown, recharge vectors, and pore
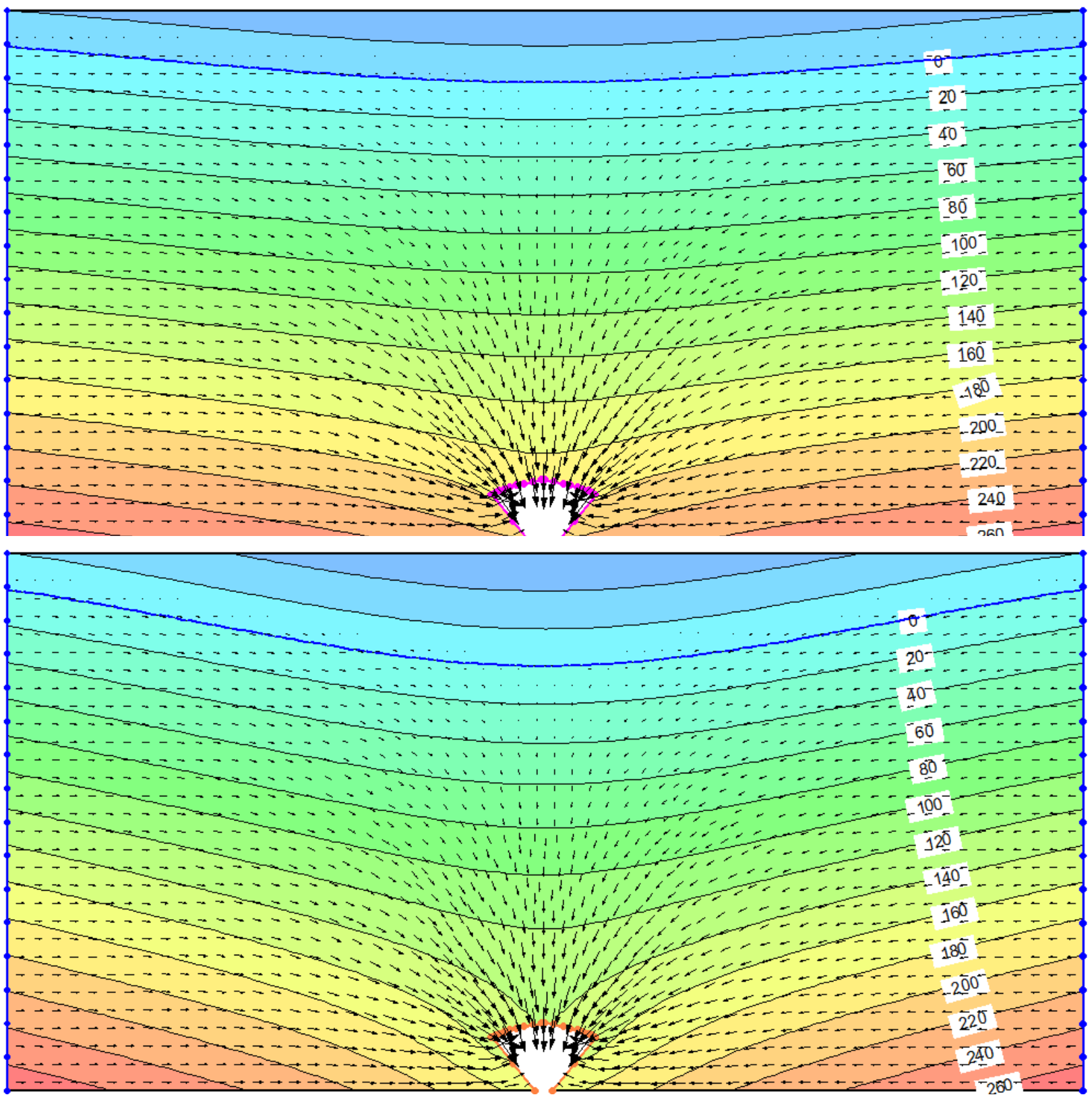

Figure 4. Cross-section showing groundwater drawdown (blue line), flow vectors (arrows), and pore pressure distribution (colored background) at different groundwater conditions (a) Head Difference $=5 \mathrm{~m}$ (b) Head Difference $=10 \mathrm{~m}$ (Continued on next page) 
water pressure distribution corresponding to each head difference value at steady-state. A concentration of the flow (recharge) vectors is noticed at the top corners of the cavity. Therefore, the highest seepage forces take place at these locations. This explains the behavior of cavity growth which usually tends to evolve from the corners as observed in the experimental investigation.
This behavior can also be related to the effective stress redistributions around the cavity, which are explored in the following sections of this research.

\section{Discussion and Results}

Figure 5 display the effective vertical stress distribution for all the studied conditions in this research. A stress

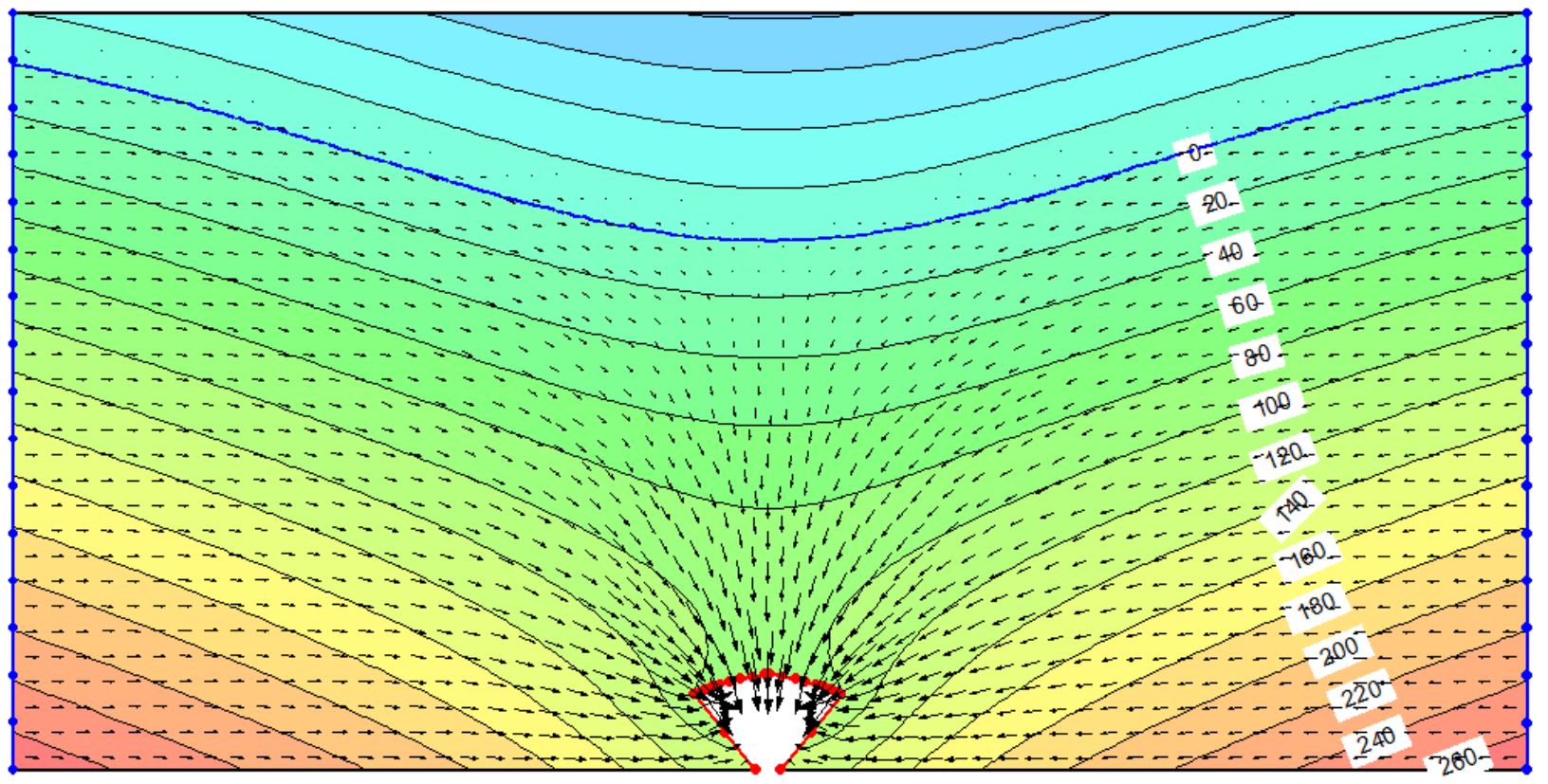

Figure 4. Cross-section showing groundwater drawdown (blue line), flow vectors (arrows), and pore pressure distribution (colored background) atdifferentgroundwaterconditions. (c) HeadDifference= $15 \mathrm{~m}$

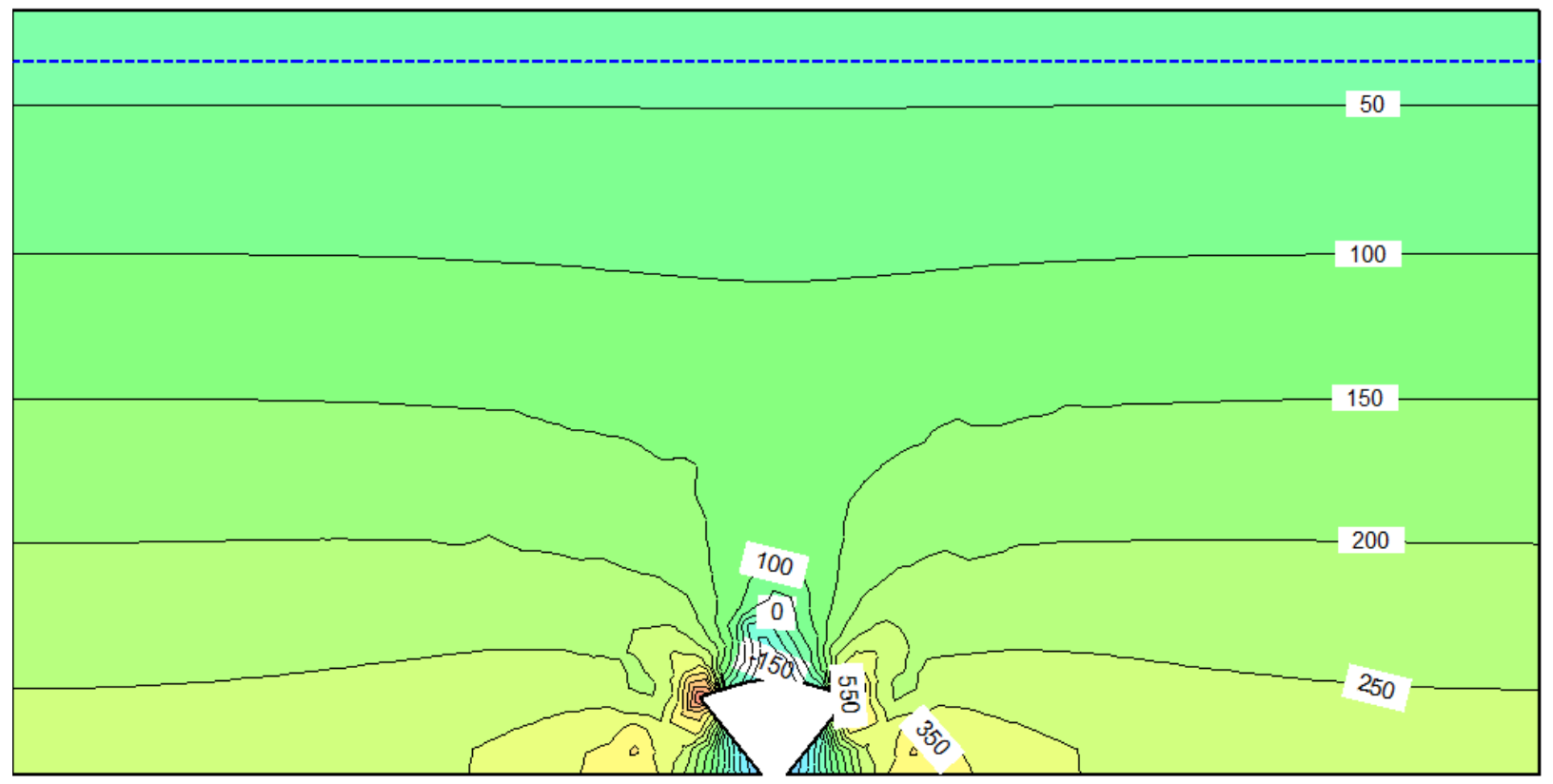

Figure 5. Effective stress distribution at different groundwater conditions. (a) Hydrostatic Condition (Continued on next page) 

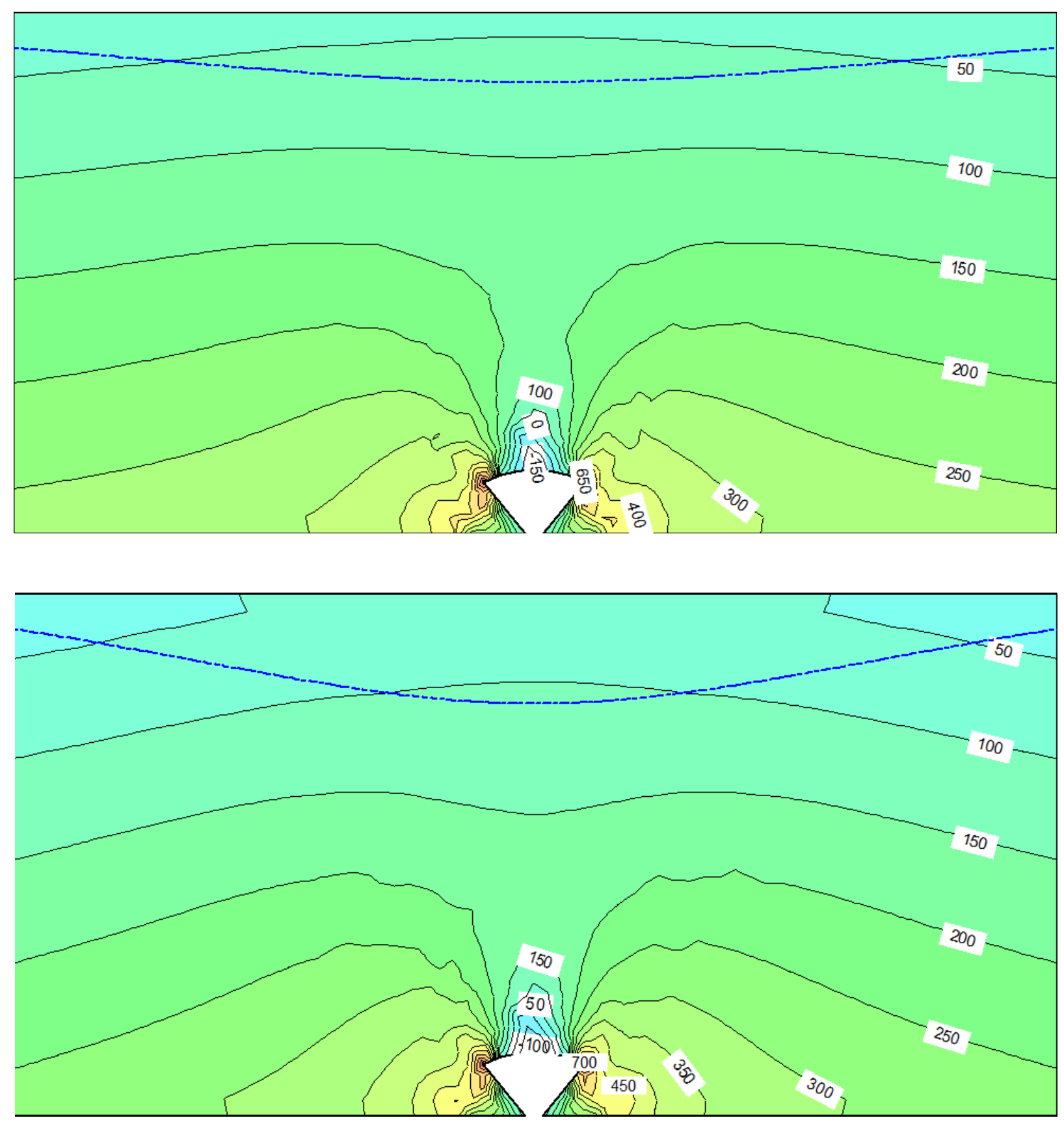

Figure 5. Effective stress distribution at different groundwater conditions. (b) Head Difference $=5 \mathrm{~m}$ (c) Head Difference $=10 \mathrm{~m}$ (Continued on next page) 


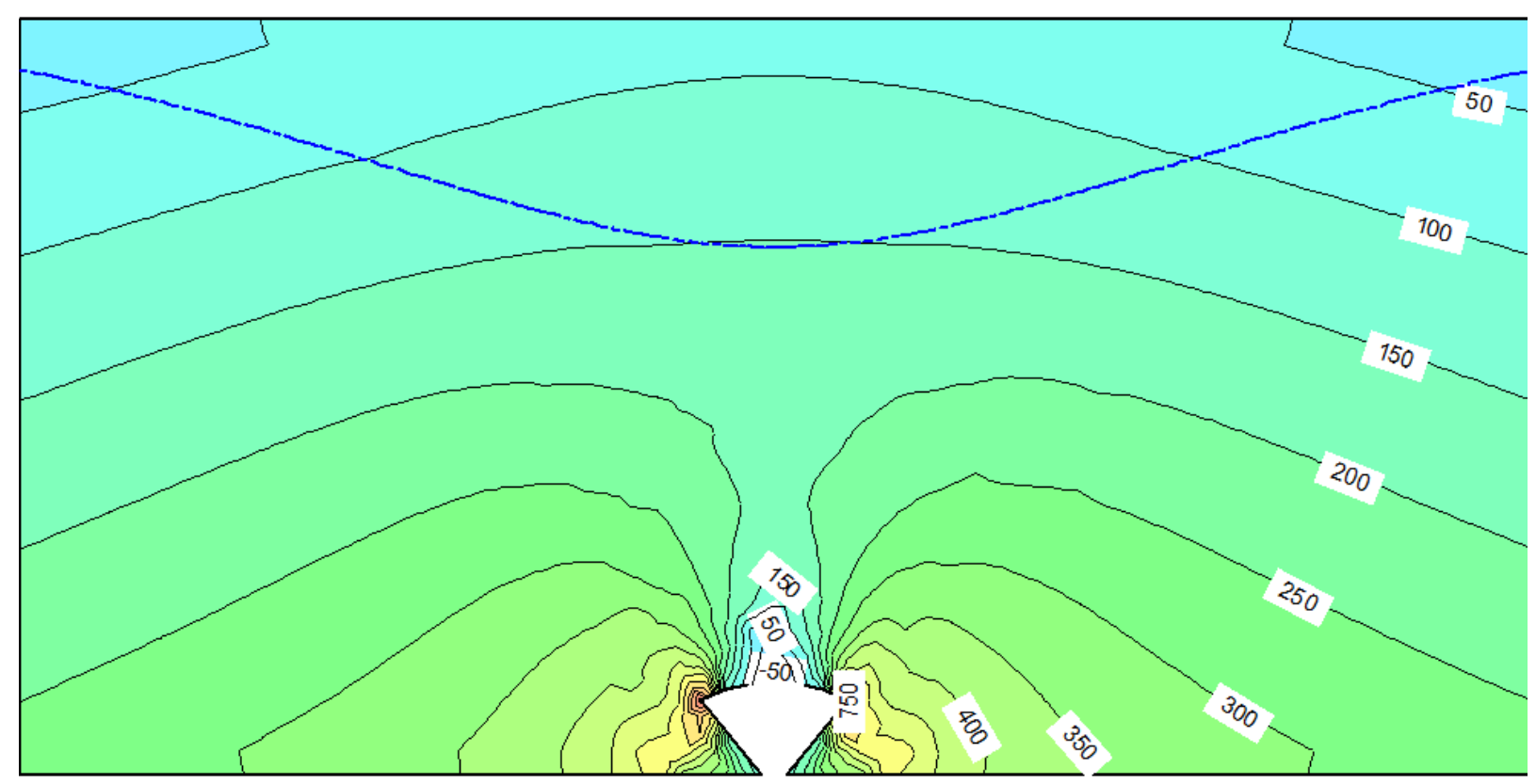

Figure 5. Effective stress distribution at different groundwater conditions. (d) Head Difference $=15$ $m$

redistribution is observed around the cavity. A drop in the stress occurs on the top of the cavity along its center. The stresses are transferred to the corners of the cavity where stress concentrations take place. This behavior is due to the arching effect which governs the stress redistributions taking place around any underground opening (Tien, 1996).

Figure 6 presents the pore water pressure (pwp) with depth above the cavity at different groundwater conditions. The change in pwp values is $50 \mathrm{kPa}$ at the cavity top which corresponds to a $5 \mathrm{~m}$ head difference, where the water density is $10 \mathrm{kN} / \mathrm{m}^{3}$. It is observed that the change in pwp decreases to $20 \mathrm{kPa}$ at depths closer to the ground surface. The negative pwp values are due to capillary rise (suction) which is considered by the SEEP/W analysis. Figure 7 and 8 show the effective vertical stress distribution by depth above the center and the corners of the cavity, respectively, to emphasize on the changes due to the different recharge conditions. In Figure 7, the effective stress increases with depth until it reaches a peak value at a depth around $14 \mathrm{~m}$, then it significantly decreases. In Figure 8, the effective stress increases with depth, and a drastic increase starts to occur from a depth of $14 \mathrm{~m}$ to the top of the cavity. Therefore, the decrease of stresses above the center is compensated by the increase of stresses above the corners along the same depths. An increase in the effective stress values is observed as the head difference increases. This increase ranges between $20 \mathrm{kPa}$ and $30 \mathrm{kPa}$ for each $5 \mathrm{~m}$ increase of head difference.

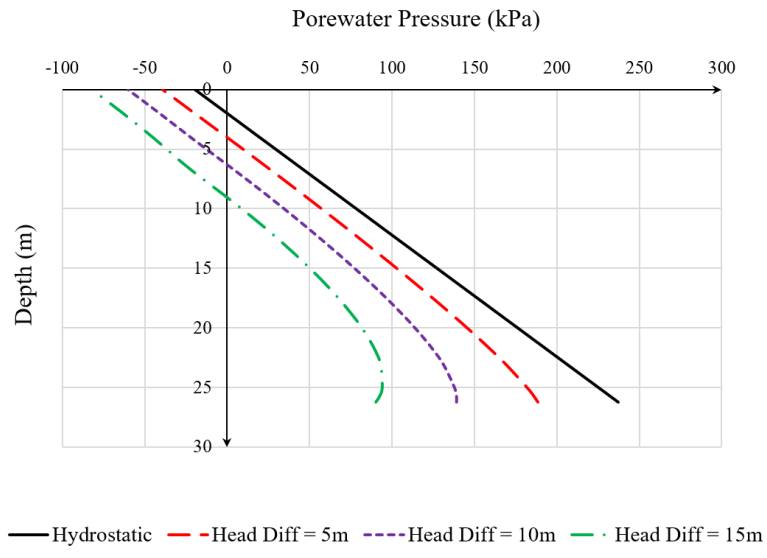

Figure 6. Porewater pressure above the cavity

\section{Stress Paths Around Cavity}

Stress changes at the corners of the cavity due variation in groundwater conditions are investigated for different cavity sizes. The cavity has the same inverted triangular shape (angle $=51^{\circ}$ ) with two different heights used in this analysis: $4 \mathrm{~m}$ and $8 \mathrm{~m}$. The $8 \mathrm{~m}$ height cavity is also assessed when the angle of its sides changes to $66^{\circ}$ with the horizontal. The same model dimensions (60 $\mathrm{m}$ width and $30 \mathrm{~m}$ height) are used for each analysis. Thus, the overburden depths above the $4 \mathrm{~m}$ height and the $8 \mathrm{~m}$ height cavities are: $26 \mathrm{~m}$ and $22 \mathrm{~m}$, respectively. The Mohr-Coulomb (MC) model is used with the same parameter values as listed in Table 1. The MC failure envelope is defined in the MIT Stress-Space as shown 


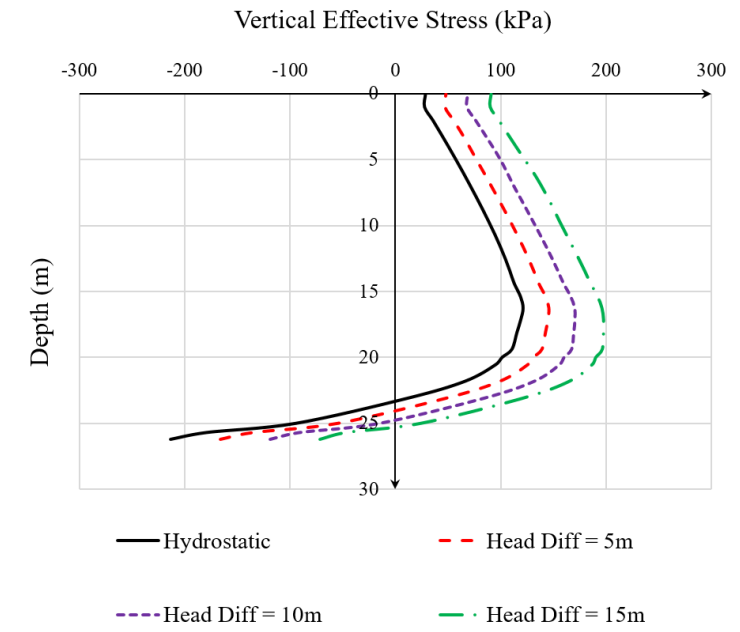

Figure 7. Effective vertical stress above center of the cavity

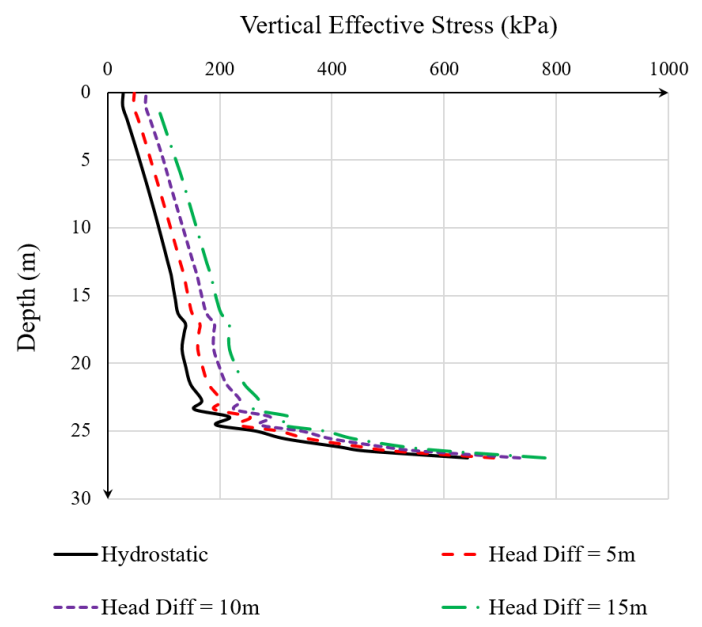

Figure 8. Effective vertical stress above the corners of the cavity

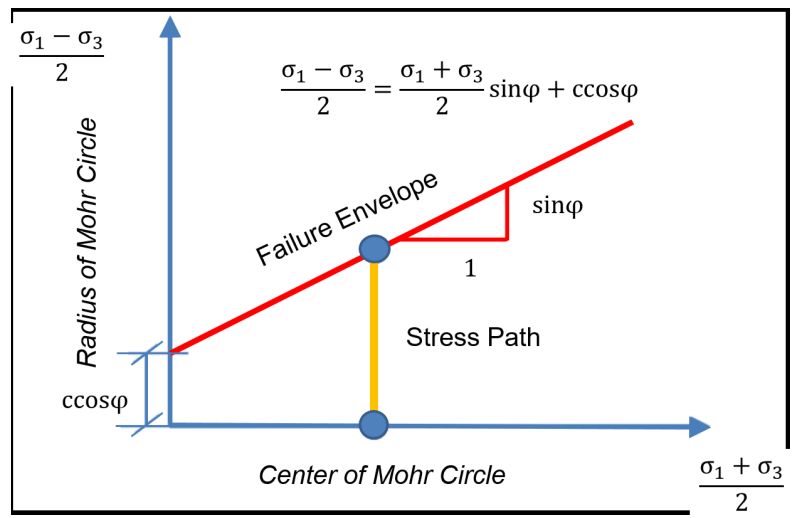

Figure 9. Failure surface of Mohr-Coulomb model in MIT stress-space (AKl, 2015) in Figure 9, where the mean effective stress (p') is $(\sigma 1+\sigma 3) / 2$, and the deviator stress $(q)$ is $(\sigma 1-\sigma 3) / 2$.

The stress paths at the corners of the cavity are plotted on the MIT Stress-Space for the different subterranean conditions in this analysis (Figure 10). It is observed that for different cavity sizes the mean effective stress (p') increases as the groundwater table is lowered with a relatively insignificant increase in the deviatoric stress (q). A significant change in the stress path is noticed when the side angles of the cavity change. Both p' and $q$ values increase when the side angles increase from $51^{\circ}$ to $66^{\circ}$ at a constant cavity height. It is also noticed that p' and q values at the corners of the $8 \mathrm{~m}$ cavity are significantly larger than those at the corners of the $4 \mathrm{~m}$ height cavity, however, the overburden depth is smaller in the former case.

\section{Summary and Conclusion}

In this paper, the sinkhole formation due to subsurface cavities was assessed by experimental and numerical means. The research emphasized cover-collapse sinkholes in Central Florida. A physical model involving an unconfined aquifer and a confined aquifer was carried out, and the different stages of sinkhole evolution due to a fracture in the soil bottom were visually monitored. An inverted triangle-shaped cavity grows upwards due to soil erosion at its corners until collapse occurs.

In a stress-seepage coupled analysis, the cavity shape observed in the physical model was used to investigate numerically the effects of groundwater conditions and

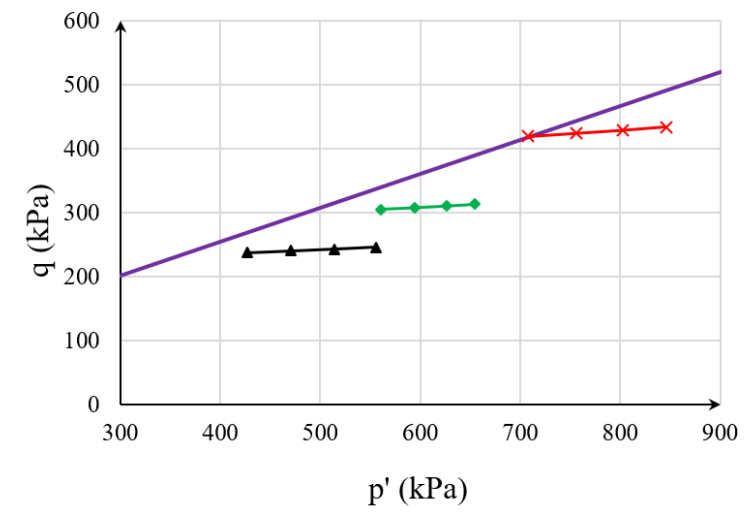

$$
\begin{aligned}
& \longrightarrow \mathrm{MC} \text { Yield } / \text { Failure Surface } \\
& \leftarrow \text { Cavity Height }=4 \mathrm{~m} \\
& * \text { Cavity Height }=8 \mathrm{~m} \\
& \multimap \text { Cavity Height }=4 \mathrm{~m}, \text { Angle }=66
\end{aligned}
$$

Figure 10. Stress relations at the corners of the cavity for various scenarios 
cavity size on stress conditions. The study showed that a stress redistribution takes place around the cavity due to the soil arching effect. The effective stress increases significantly at the corners to compensate for the stress reduction that takes place above the center of the cavity. According to the seepage analysis, downward seepage due to a head drop in the confined aquifer results in the highest recharge values occurring at the corners of the cavity, and thus, the highest seepage forces exist at these locations.

The stress paths at the corners of the cavity were investigated at different groundwater conditions and cavity sizes. The analysis shows that increasing groundwater table causes the stress path closer to the failure envelope, which is more unstable condition. When the cavity height increases, both the mean effective and the deviator stresses increase towards the yields surface. A change in the side angles of the cavity or its shape affects the stress conditions around the cavity.

\section{References}

Akl SA. 2015. Redistribution of stresses due to drilling and depletion using different plasticity models. 49th US Rock Mechanics/Geomechanics Symposium. American Rock Mechanics Association.

Drumm EC, Akturk O, Tutluoglu L. 2009. Stability charts for the collapse of residual soil in karst. Journal of Geotechnical and Geoenvironmental Engineering 135 (7): 952-931.

Newton JG. 1976. Induced sinkholes - a continuing problem along Alabama highways. Proceedings of International Association of Hydrogeological Sciences 21: 453-463.

Newton JG. 1984. Natural and induced sinkhole development in the Eastern United States. Proceedings of the Third International Symposium on Land Subsidence, Venice, Italy: 549-564.

Newton JG, Hyde LW. 1971. Sinkhole problem in and near Roberts Industrial Subdivision, Birmingham, Alabama. Alabama Geological Survey Circular 68.

Perez AL., Nam BH, Alrowaimi M, Chopra M, Lee SJ, Youn H. 2017. Experimental study on sinkholes: soil-groundwater behaviors under varied hydrogeological conditions. Journal of Testing and Evaluation 45 (1): 208-219.

Perez AL, Nam BH, Chopra M, Sallam A. 2017. Understanding Florida's sinkhole hazards: hydrogeological laboratory study. Proceedings of Geotechnical Frontiers 2017: Geotechnical Materials, Modeling, and Testing, ASCE GSP 280, 508-518.

Tao X, Ye M, Wang X, Wang D, Pacheco Castro R, Zhao J. 2015. Experimental and numerical investigation of sinkhole development and collapse in Central Florida. In: Doctor DH, Land L, Stephenson JB, editors. Sinkholes and the Engineering and Environmental Impacts of Karst: Proceedings of the Fourteenth Multidisciplinary Conference, October 5-9, Rochester, Minnesota: NCKRI Symposium 5. Carlsbad, New Mexico: National Cave and Karst Research Institute, p. 501-506.

Terzaghi K. 1943. Theoretical Soil Mechanics. p. 67.

Tien HJ. 1996. A literature study of the arching effect [master's thesis]. Massachusetts Institute of Technology.

Whitman D, Gubbels T, Powell L. 1999. Spatial interrelationships between lake elevations, water tables, and sinkhole occurrence in Central Florida: a GIS approach. Photogram. Eng. Remote Sensing 65(10): 1169-1178.

Wilson WL, Beck BF. 1992. Hydrogeologic factors affecting new sinkhole development in the Orlando Area, Florida. Ground Water 30(6): 918-930.

Yang MZ, Drumm EC. 2002. Stability evaluation for the siting of municipal landfills in karst. Engineering Geology 65: 185-195. 


\section{NCKRI SYMPOSIUM 7 15TH SINKHOLE CONFERENCE}

